\title{
Comparative study of the most efficient maximum power point tracking techniques for a photovoltaic system
}

\author{
I. M. Abdel-Qawee' ${ }^{1}$, H. G. Hamed ${ }^{2}$, Maged N. F. Nashed ${ }^{3}$, Ayman Y. Yousef $^{4}$, Khaled M. Hasaneen $^{5}$ \\ ${ }^{1,2,4,5}$ Electrical Engineering Department, Faculty of Engineering at Shoubra, Benha University, Egypt \\ ${ }^{3}$ Department of Power Electronics and Energy Conversion, Electronics Research Institute, Egypt
}

\begin{tabular}{l} 
Article Info \\
\hline Article history: \\
Received Dec 7, 2018 \\
Revised Feb 5, 2019 \\
Accepted Feb 20, 2019 \\
\hline Keywords: \\
Fuzzy logic control \\
Genetic algorithm \\
Incremental conductance \\
MPPT \\
Photovoltaic \\
\hline
\end{tabular}

\begin{abstract}
In Photovoltaic (PV) systems, maximum power point tracking (MPPT) is an important challenge which faces this system. In this paper, a comparative study between two high efficient MPPT control techniques is presented. These techniques are based on the incremental conductance (IC) method. The first technique is based on optimized PI-controller gains and the other is based on Fuzzy Logic Control (FLC). The comparison between the algorithms is investigated under different environmental conditions. The comparison criteria which are taken into consideration are: the percentage tracking factor $(\% \mathrm{TF})$, the tracking time, the ripple voltage in the steady-state, the dynamic response, and the complexity of implementation.
\end{abstract}

\section{Corresponding Author:}

I. M. Abdel-Qawee,

Electrical Engineering Department, Faculty of Engineering at Shoubra,

Benha University,

108 Shoubra street, Cairo, Egypt.

Email: islam.ahmed@feng.bu.edu.eg

\section{INTRODUCTION}

One of the drawbacks of the PV system that the PV module conversion efficiency is low (only in the range from $12 \%-22 \%$ ) [1]. Also, its efficiency is influenced by the change in the irradiance level and the cell temperature. Therefore, the maximum power obtained from the PV module for any electrical load should be extracted by using MPPT control at any irradiance level and cell temperature to improve the conversion efficiency of the PV module.

The MPPT control techniques differ according to the required sensors, cost, control complexity, the time elapsed to reach the MPP (tracking time), and the required accuracy [2]. The MPPT control techniques can be divided into two categories, according to the accuracy, namely direct and indirect techniques [3]. Direct techniques are independent on previous knowledge about the PV modules characteristics, such as perturb and observe (P\&O) method, incremental conductance method, fuzzy logic control method and artificial neural network (ANN) method. Indirect techniques need previous evaluation of PV module which is based on mathematical relationship obtained from empirical data; such as look-up table, open-circuit PV voltage, and short circuit PV current.

The most usual MPPT control techniques also can be classified according to the implementation simplicity. The techniques can be divided into two main groups, [4]. The first group contains the conventional techniques such as: constant voltage method $[2,5]$, fractional open-circuit voltage and fractional short-circuit current methods [6,7], perturb and observe method [2, 7-9], and incremental conductance method [2, 5, 10]. The other group contains the techniques which depend on the artificial intelligent (AI) techniques such as: Fuzzy logic control method [11, 12], and artificial neural network method [6]. 
In this paper, a comparative study of the most efficient MPPT control techniques are investigated. These techniques are based on the concept of the IC method. The first technique is based on optimized PIcontroller gains and the other is based on FLC. The paper is organized as follows: in section 2, modelling and simulation of the PV module under changing the environment conditions using Matlab/Simulink and the concept of MPPT controllers are presented. In section 3, the proposed MPPT techniques based on IC are investigated. In section 4, a comparative study between the MPPT controllers are carried out under various scenarios in weather conditions. Finally, the main conclusion about each MPPT control technique are presented in the last section.

\section{MODELING AND SIMULATION OF A PV MODULE}

There are different electrical equivalent mathematical models used to describe the PV module. Some of these models are based on single-diode and two-diode models [13]. Due to simple implementation, less simulation time, and high efficient way for MPPT, the single-diode model is represented as shown in Figure 1, [2, 13-15]. The current source $I_{p h}$ represents the module photocurrent. $R_{s}$ and $R_{s \mathrm{~h}}$ are series and intrinsic shunt resistances of the module respectively that represent the cell losses. The current losses due to recombination losses in the cell are represented by the shunt diode.

The current model of a PV module can be expressed as [16]:

$$
I_{P V}=I_{p h}-I_{o}\left[\exp \left(\frac{V_{P V}+I_{P V} R_{s}}{a N_{s} V_{t}}\right)-1\right]-\frac{V_{P V}+I_{P V} R_{s}}{R_{s h}}
$$

And the power of a PV module can be obtained from:

$$
\begin{aligned}
P_{P V} & =V_{P V} I_{P V} \\
& =V_{P V}\left[I_{p h}-I_{o}\left[\exp \left(\frac{V_{P V}+I_{P V} R_{s}}{a N_{s} V_{t}}\right)-1\right]-\frac{V_{P V}+I_{P V} R_{s}}{R_{s h}}\right]
\end{aligned}
$$

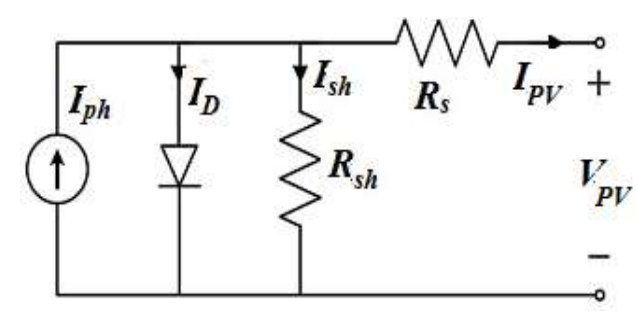

Figure 1. Equivalent circuit of a single-diode solar cell model

The I-V and P-V characteristics of the PV module are obtained when the cell temperature (T) and irradiance level (G) are changed and compared with those given in the KC200GT PV module datasheet, [17]. Figure 2 shows the simulation results taking into account the effect of changing the cell temperature on the I$\mathrm{V}$ and P-V characteristics of the PV module. The effect of changing the irradiance levels on the I-V and P-V characteristics of the module are shown in Figure 3.

Due to the high capital cost of PV modules, DC-DC converters with MPPT control techniques are essential in order to extract the maximum output power from the PV module under any weather condition. Usually the boost converter, Figure 4, is used as the required output voltage is higher than the PV output voltage. Therefore, number of the series PV modules is reduced when using the boost converter, and consequently, the cost of the PV system will be reduced [10]. The PV module output current is always continuous which is essential for efficient MPPT [18, 19].

There are many methods used to control the duty cycle of the boost converter to operate at the maximum power point (MPP) of the PV module. The IC method is one of the well-known methods [2]. This method is based on the fact that the slope of the P-V curve of the PV module is equal to zero at the MPP, i.e $\mathrm{dP}_{\mathrm{PV}} / \mathrm{dV}_{\mathrm{PV}}=0$, positive in the left of the MPP, and negative in the right of the MPP. From this fact, the MPP can be found in terms of the IC of the PV module by the following expressions.

Int. J. of Adv. in Appl. Sci. Vol. 8, No. 1, March 2019: 73 - 82 
Int. J. of Adv. in Appl. Sci.

$$
\begin{aligned}
& \frac{d P}{d V}=\frac{d\left(V_{P V} I_{P V}\right)}{d V_{P V}}=I_{P V}+V_{p V} \frac{d I_{P V}}{d V_{P V}}=0 \\
& \therefore \frac{\Delta I_{P V}}{\Delta V_{P V}}=-\frac{I_{P V}}{V_{P V}} \\
& \text { or } \frac{\Delta I_{p V}}{\Delta V_{p V}}>\frac{I_{p V}}{V_{p V}} \\
& \text { or } \frac{\Delta I_{P V}^{p V}}{\Delta V_{P V}}<\frac{I_{P V}^{p V}}{V_{P V}}
\end{aligned}
$$

Where: (a) represents the condition at the MPP, (b) represents the condition in the left of the MPP, and (c) represents the condition in the right of the MPP. The flowchart which describes this algorithm is shown in Figure 5 [20]:

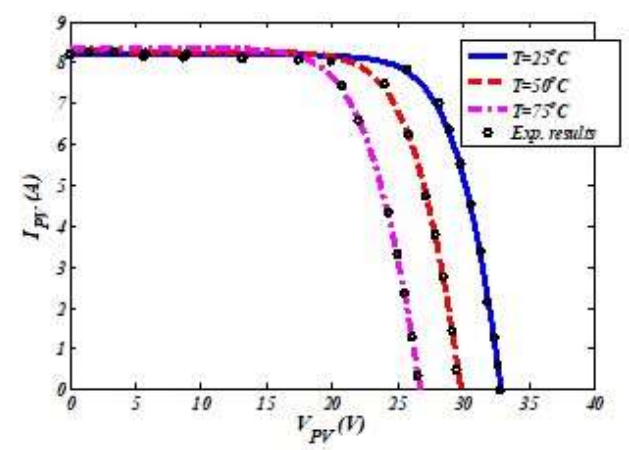

(a)

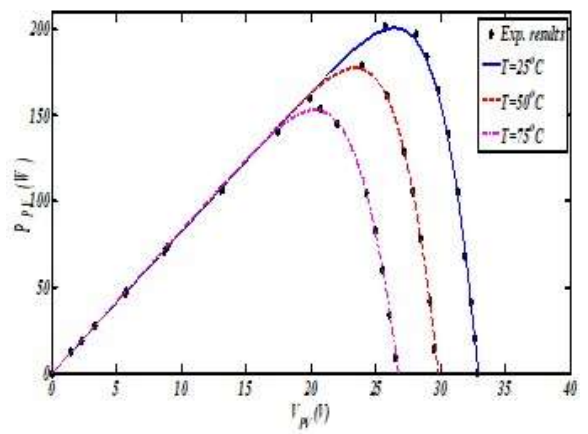

(b)

Figure 2. I-V and P-V characteristics of the PV module at $\mathrm{G}=1000 \mathrm{~W} / \mathrm{m}^{2}$ and varying $\mathrm{T}$.

(a) I-V curves, (b) P-V curves of the PV module

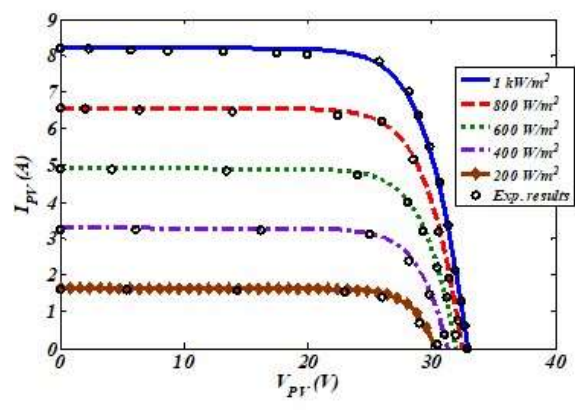

(a)

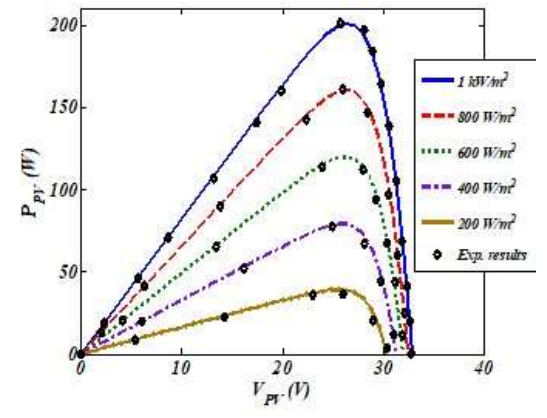

(b)

Figure 3. I-V and $\mathrm{P}-\mathrm{V}$ characteristics of the $\mathrm{PV}$ module at $\mathrm{T}=25^{\circ} \mathrm{C}$ and varying irradiation level. (a)I-V curves, (b) P-V curves of the PV module

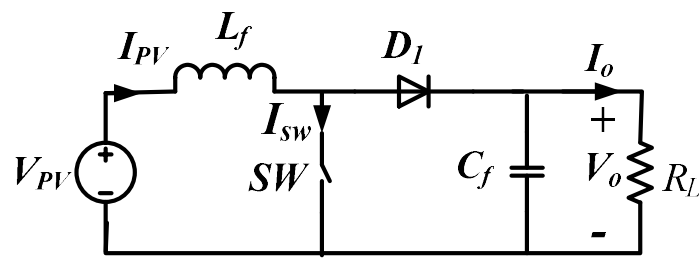

Figure 4. Boost converter 


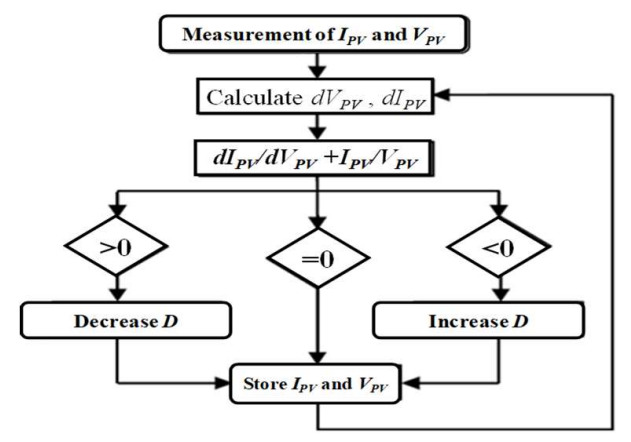

Figure 5. Flowchart of the incremental conductance method

To improve the performance of the IC method and making it an adaptive, the IC method with conventional PI-controller gains can be used [2]. The basic idea of this algorithm is that the summation of the conductance and the IC (e), as obtained in (4), is equal to zero at the MPP, [6]. Therefore, this idea is used to generate an error signal as an input to a simple PI-controller. This error signal should be zero at the $\operatorname{MPP}[2,6]$.

$$
e=\frac{I_{P V}}{V_{P V}}+\frac{\Delta I_{P V}}{\Delta V_{P V}}
$$

Simulink block diagram of this algorithm is shown in Figure 6. The error signal is compared to zero and the result is the input of the PI-controller which generates the desired duty cycle [2].

The PV module power response using this algorithm is shown in Figure 7. The proportional and integral controller gains $\left(\mathrm{K}_{\mathrm{p}}, \mathrm{K}_{\mathrm{I}}\right)$ are selected to be 0.1 and 20 respectively, using the trial and error process, such that the tracking time and the maximum peak-to-peak power fluctuation $\left(\Delta P_{P V, \max }\right)$ are minimized. It can be seen from this figure that the $\Delta P_{P V, \max }$ in the steady state is nearly zero at all conditions of irradiance levels. The maximum tracking time $\left(\mathrm{t}_{\text {track }}\right)$ is $(34 \mathrm{msec})$ at start up, where the irradiance level at $0.8 \mathrm{p}$.u, while in the case of suddenly change of the irradiance level from 0.8 p.u. to 0.6 p.u and from 0.6 to 1 p.u., the $t_{\text {track }}$ is (18 $\mathrm{msec})$ and $(14 \mathrm{msec})$ respectively. However, the $t_{\text {track }}$ is $(60 \mathrm{msec})$ when the irradiance level is suddenly changed from 1 p.u to 0.4 p.u.

The effect of changing the controller gains of the PI-controller on the PV module power response is shown in Figure 8. Keeping $\mathrm{K}_{\mathrm{P}}=0.1$, if $\mathrm{K}_{\mathrm{I}}$ is increased from 20 to be 35, the tracking time will be reduced and if it is decreased from 20 to be 5, the tracking time will be increased with slight effect on the $\Delta P_{P V, \max }$ as shown in Figure 8(a). While changing the proportional gain with keeping $\mathrm{K}_{\mathrm{I}}=20$ has a slight effect on the tracking time and the $\Delta P_{P V, \max }$ as shown in Figure $8(\mathrm{~b})$.

It can be concluded from these simulation results that there are optimal values for $K_{P}$ and $K_{I}$ at which the PI-controller gives the best response. These optimal values can be obtained using an optimization technique. Also, it can be noticed that the proportional gain has a minor effect compared to the integral gain. Therefore, in the proposed technique, the integral PI-controller gain will be determined using the genetic algorithm (GA) optimization technique. Details of this algorithm is discussed in detail in the next section.

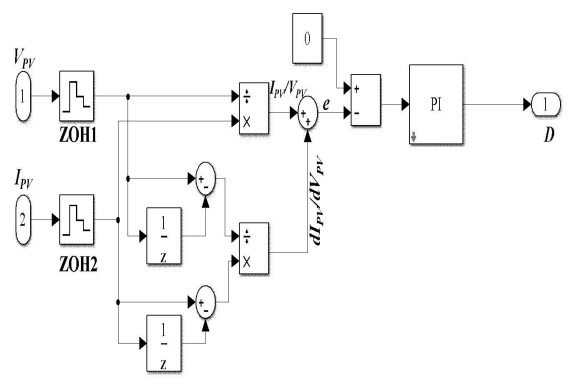

Figure 6. Simulink block diagram of the IC method based on PI-controller

Int. J. of Adv. in Appl. Sci. Vol. 8, No. 1, March 2019: 73 - 82 


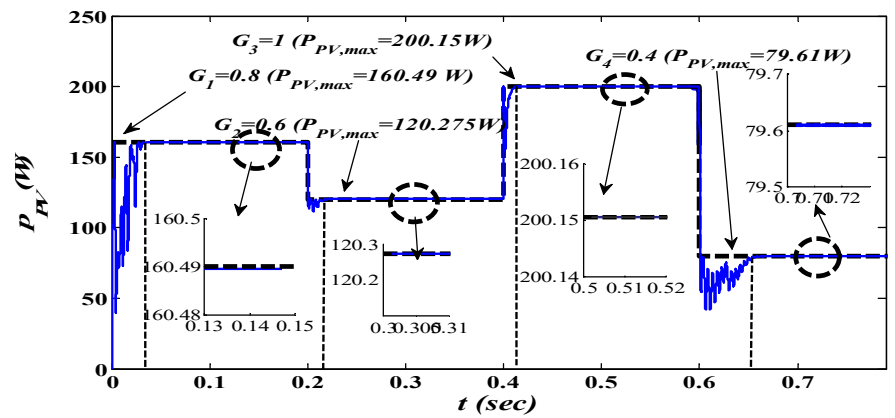

Figure 7. PV module power response of the IC method with PI-controller, at $\left(\mathrm{K}_{\mathrm{P}}=0.1\right.$ and $\left.\mathrm{K}_{\mathrm{I}}=20\right)$

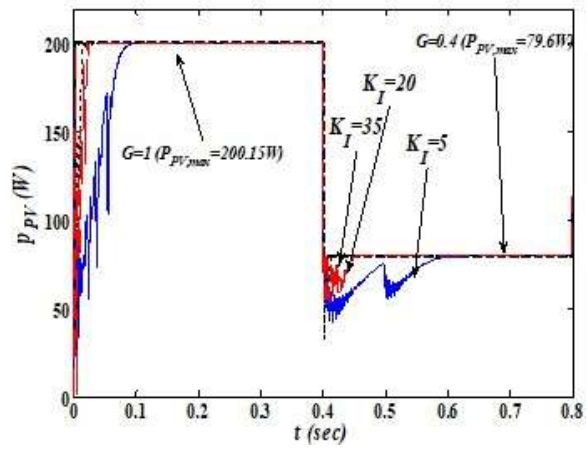

(a)

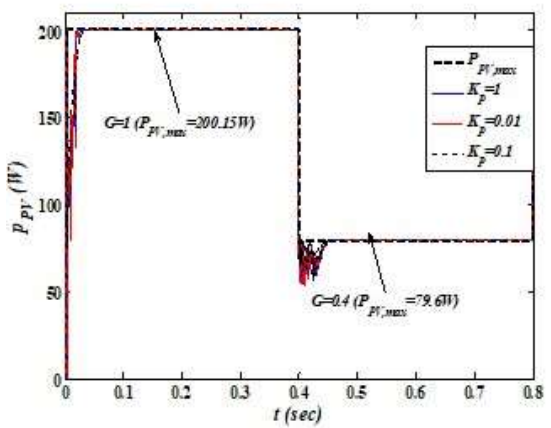

(b)

Figure 8. PV module power response of the IC method with PI-controller at, (a) different values of integrator gain, (b) different values of proportional gain

\section{THE PROPOSED MPPT TECHINQUES}

\subsection{Incremental conductance method with optimized PI-controller gains}

As mentioned before, the integral control gain of the PI-controller has the major effect on the tracking time compared to the proportional gain. Therefore, in this algorithm, the GA optimization technique is used to select the optimal value of the integral control gain of the PI-controller. Flowchart of the algorithm is shown in Figure 9.

To improve the performance of the PV module power response, the GA is used offline to obtain two values of $\mathrm{K}_{\mathrm{I}}$, at low irradiance level (less than 0.5 p.u.) and at high irradiance level (above 0.5 p.u.). The obtained values of $\mathrm{K}_{\mathrm{I}}$ at the lowest irradiance level ( 0.2 p.u.) and at the highest irradiance level (1 p.u.) are found to be (45.5) and (20.3) respectively.

Simulink block diagram of this algorithm is shown in Figure 10. The signal error (e) is compared to zero and the result, error, is the input of the discrete PI-controller with optimal integral gains. Where in the "discrete integral block" $T_{s}$ is the controller sampling time. The appropriate integral gain depends on the value of the irradiance level that is measured using an irradiance level sensor $(\mathrm{G})$. The value of $\mathrm{K}_{\mathrm{p}}$ is assumed constant $(0.1)$ at any irradiance level.

The PV module power response using this algorithm is shown in Figure 11. It can be seen from this figure that the power fluctuations in the steady state is nearly zero at all irradiance levels. The tracking time is (34 msec) at the irradiance level 0.8 p.u. The tracking times in the case of suddenly change from 0.8 p.u. to 0.6 p.u. and from 0.6 p.u. to 1 p.u. are $(18 \mathrm{msec})$ and $(14 \mathrm{msec})$ respectively. The tracking time is $(50 \mathrm{msec})$ when the irradiance level is suddenly changed from 1 p.u to 0.4 p.u.

The comparisons between the power response of the PV module using IC method with conventional integral gain and with optimal integral gains are shown in Figure 12. The figure shows that both algorithms are nearly identical when the irradiance levels are above 0.5 p.u., where the integral control gain in both algorithms is nearly 20. However, at low irradiance levels (less than 0.5 p.u.), the IC method with optimal integral gain has lower tracking time than that with conventional integral gain.

Comparative study of the most efficient maximumpower point tracking techniques ... (I. M. Abdel-Qawee) 


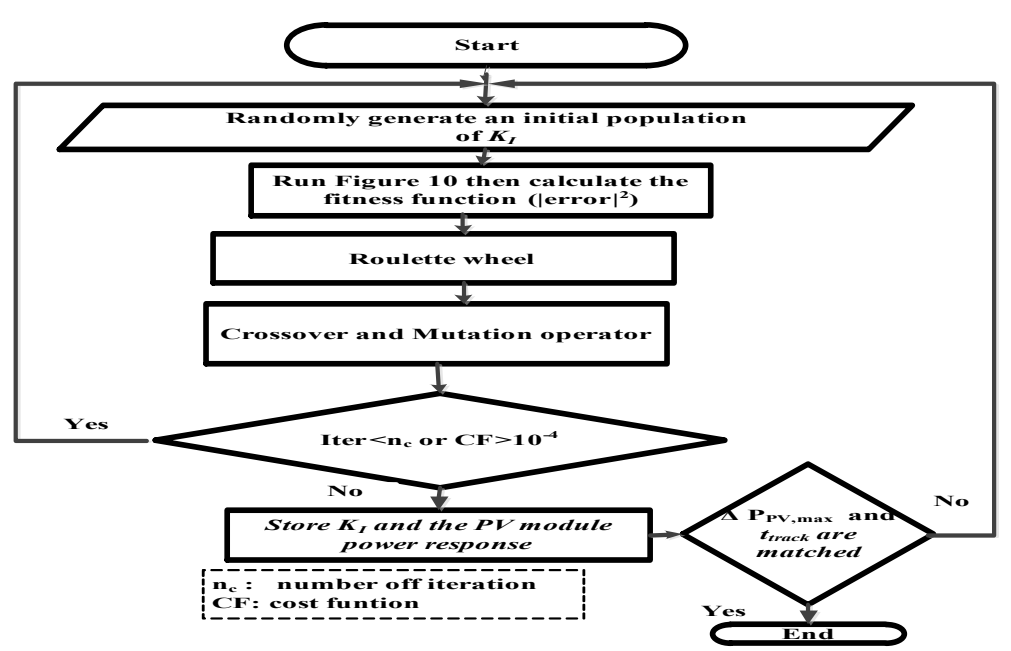

Figure 9. Flowchart of the GA optimization technique

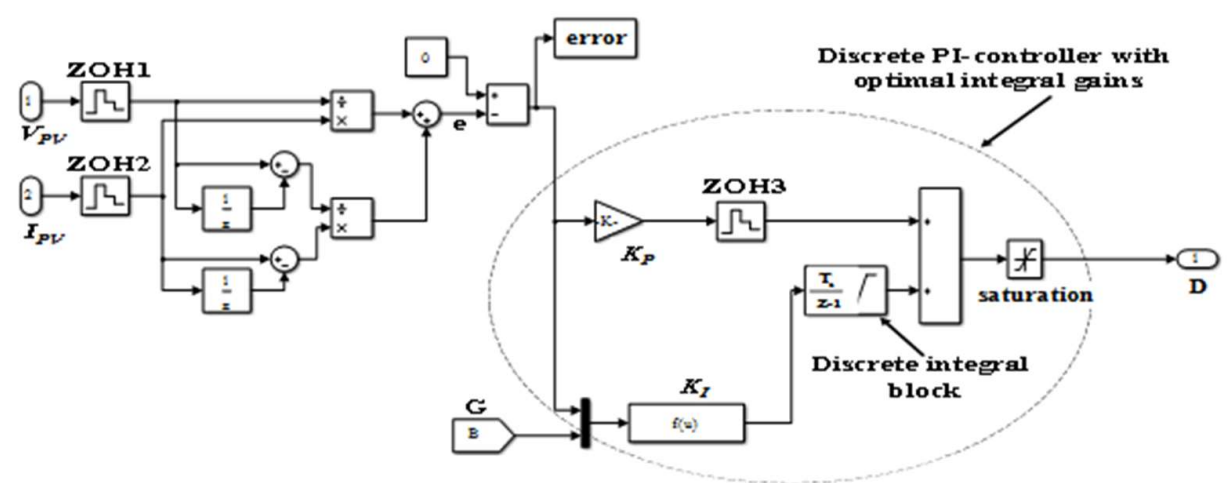

Figure 10. Simulink block diagram of the IC method based on optimized PI-controller gains

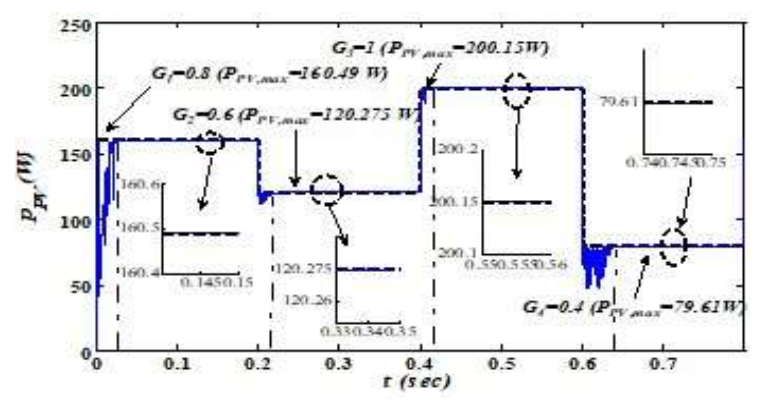

Figure 11. PV module power response of the IC method with optimized PI-controller gains at $\mathrm{K}_{\mathrm{P}}=0.1$ and $\mathrm{K}_{\mathrm{I}}=20.3$ at $(\mathrm{G}>0.5$ p.u. $), \mathrm{K}_{\mathrm{I}}=45.5$ at $(\mathrm{G}<0.5$ p.u. $)$

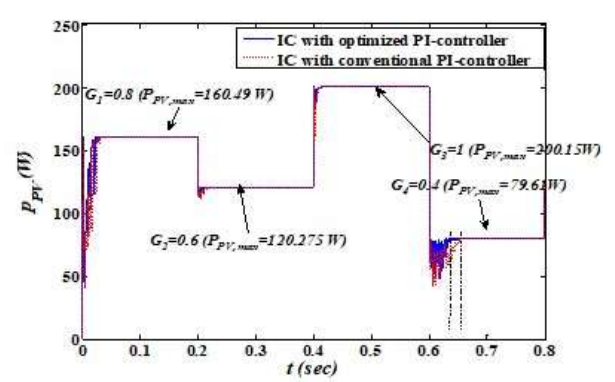

Figure 12. PV module power response of the IC method with optimized and conventional PI-controller gains

\subsection{Incremental conductance method based on fuzzy logic controller}

FLC, in general, is one of the most powerful control methods which is used in many applications to improve the performance of the system $[21,22]$. In the PV system, FLC is able to design an adaptive step size of the duty cycle without having knowledge of the mathematical model of the system, even if the system has nonlinearity behaviour. The effectiveness of the FLC MPPT algorithm depends on the input and output 
variables which are selected for the system. The output variable of the FLC algorithm is the change in the duty cycle $(\Delta \mathrm{D})$ command that will be added to the duty cycle at the pervious step. There are different methods to select the input variables of the FLC, [23].

Simulink block diagram of this method is shown in Figure 13. The figure shows that the input signal of the FLC block is generated based on the IC method (applying (4)) and the output of the FLC block is the change in the duty cycle which is added to the duty cycle at the previous step.

The PV module power response using this algorithm is shown in Figure 14. It can be seen from this figure that the power fluctuations in the steady state is nearly zero at all irradiance levels. The tracking time is $(26 \mathrm{msec})$ at the irradiance level 0.8 p.u., at start up. The $t_{\text {track }}$ in the case of suddenly change from 0.8 p.u. to 0.6 p.u. and from 0.6 p.u. to 1 p.u. are $(15 \mathrm{msec})$ and $(20 \mathrm{msec})$ respectively. The $t_{\text {track }}$ is $(65 \mathrm{msec})$ when the irradiance level is suddenly changed from 1 p.u. to 0.4 p.u.

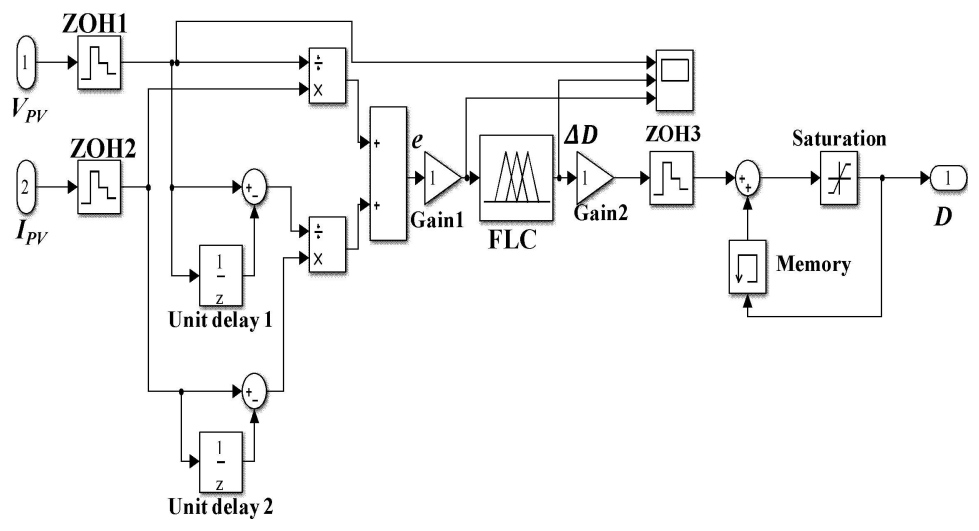

Figure 13. Simulink block diagram of the FLC based on the IC method

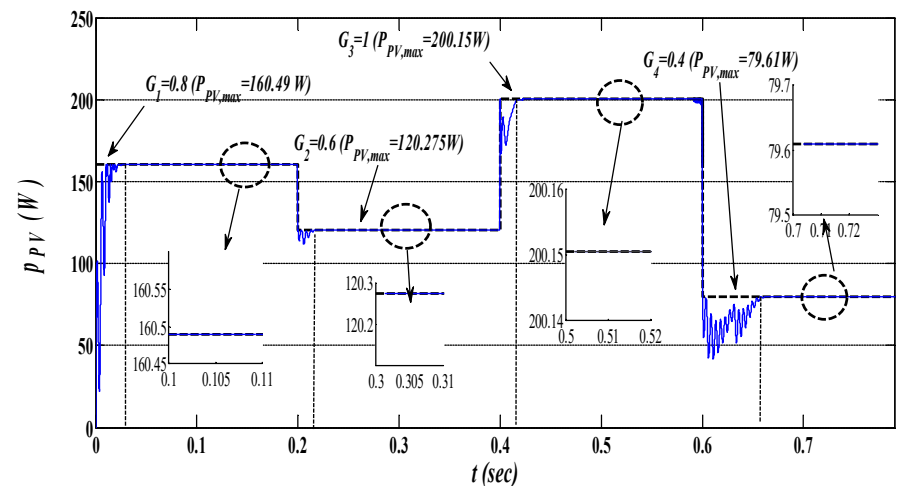

Figure 14. PV module power response of the IC method based on FLC

Comparing these results with the results in Ref. [23], it was found that the PV module is operated at the MPP, Figure 14, without any power fluctuations at all irradiance levels at steady-state due to the output of the FLC block is the change in the duty cycle comparing with Ref. [23] which has some power fluctuations at steady-state as it takes the output variable of the FLC block as the desired duty cycle. For example, considering that the irradiance level is suddenly changed from 1 p.u. to 0.4 p.u. at the same cell temperature, $25^{\circ} \mathrm{C}$, it was found that the $\Delta \mathrm{P}_{\mathrm{PV}, \max }$ is $(0.08 \mathrm{~W})$ and the $\mathrm{t}_{\text {track }}$ is $(114 \mathrm{msec})$ in Ref. [23] compared with $(0 \mathrm{~W})$ and $(65 \mathrm{msec})$ as shown in the figure.

\section{COMPARISON ETWEEN THE TECHNIQUES}

In this section, comparison between the two proposed algorithms are presented. The comparison criteria are considered to be: the percentage tracking factor, the ripple voltage in the steady-state, the dynamic response,

Comparative study of the most efficient maximumpower point tracking techniques ... (I. M. Abdel-Qawee) 
and the complexity of the implementation. To investigate these comparison criteria and selecting the best technique, the PV system will be tested under normal operating cell temperature (NOCT) and under the worst atmospheric conditions.

\subsection{Comparison under normal Ooperating cell temperature}

The performance of the PV system using the proposed algorithms under normal operating cell temperature, $\mathrm{G}=0.8$ and $\mathrm{T}=47^{\circ} \mathrm{C},[17]$, is investigated. The $\mathrm{PV}$ module power response using both algorithms is shown in Figure 15. It can be seen from the figure that the maximum extracted power using both algorithms is nearly $(142 \mathrm{~W})$ which is equal to the maximum PV module power under this operating condition, [17]. Therefore, the percentage tracking factor for both algorithms is $100 \%$. The tracking time using IC method based on FLC algorithm is ( $30 \mathrm{msec})$, while the tracking time using the IC method based on the optimized PIcontroller gains algorithm is $(40 \mathrm{msec})$. The maximum peak-to-peak power fluctuations $\left(\Delta \mathrm{P}_{\mathrm{PV}, \max }\right)$ in both algorithms is nearly zero.

The ripple voltage in the steady-state of the PV module is around $0.005 \mathrm{~V}$ using both algorithms as shown in Figure 16. However, the maximum overshoot voltage obtained using the IC method based on optimized PI-controller gains algorithm is $(32 \mathrm{~V})$ which is almost equal to that obtained using the IC method based on FLC algorithm, which is $(30 \mathrm{~V})$.

\subsection{Comparison under worst atmospheric conditions}

To investigate the robustness of the proposed MPPT control techniques with the standalone PV system under the worst atmospheric conditions, the irradiance level is suddenly changed from the highest level, 1 p.u., to the lowest level, $0.2 \mathrm{p}$.u at $\mathrm{T}=25^{\circ} \mathrm{C}$, and the cell temperature is suddenly changed from $25{ }^{\circ} \mathrm{C}$ to $75^{\circ} \mathrm{C}$ at $\mathrm{G}=1$ p.u. [17].

The effect of changing the irradiance level and the PV cell temperature, under the worst atmospheric conditions, on the PV module power response are shown in Figures 17 and 18 respectively.

It can be shown from these figures that the PV module power is nearly constant around the MPP without any power fluctuations using both algorithms at steady-state. Therefore, the percentage tracking factor in both cases is $100 \%$. However, at start up, where the irradiance level is at $1 \mathrm{p} . \mathrm{u}$. and the cell temperature is at $25{ }^{\circ} \mathrm{C}$, the tracking time using the IC method based on FLC algorithm is $(21 \mathrm{msec})$ which is less than that using the other algorithm which is $(28 \mathrm{msec})$.

When the irradiance level is suddenly changed from the highest level to the lowest level, Figure 17, the tracking time using the IC method based on optimized PI-controller gains algorithm is ( $90 \mathrm{msec})$ which is less than that using the IC method based on FLC algorithm which is $(155 \mathrm{msec})$. Also, when the cell temperature is suddenly changed from $25^{\circ} \mathrm{C}$ to $75^{\circ} \mathrm{C}$, Figure 18 , the tracking time using IC method based on optimized PIcontroller gains algorithm is $(13 \mathrm{msec})$ which is less than that using the IC method based on FLC algorithm, which is $(22 \mathrm{msec})$.

The PV module voltage response under the largest change in the irradiance level and the cell temperature are shown in Figure 19 and Figure 20 respectively. The figures show that the ripple voltage in the steady-state under the standard test condition (STC) and at $\left(\mathrm{T}=75^{\circ} \mathrm{C}, \mathrm{G}=1\right.$ p.u.) is $(0.005 \mathrm{~V})$ using both algorithms. However, the maximum ripple voltage in the steady-state when the irradiance level is change from 1 p.u. to 0.2 p.u is less than $(1 \mathrm{~V})$ using the IC method based on FLC algorithm, while it is around (2.5 V) using the IC method based on optimized PI-controller gains algorithm.

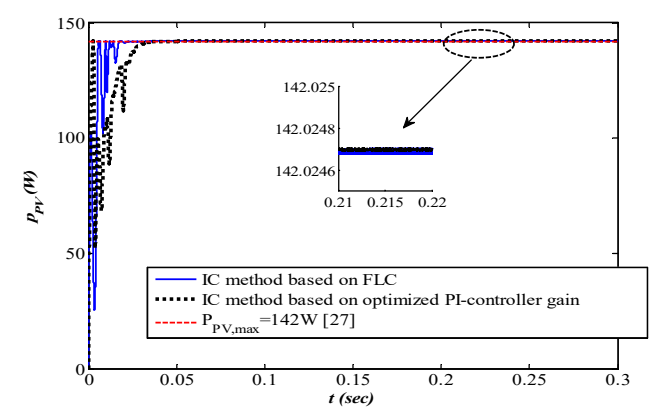

Figure 15. PV module power response under NOCT

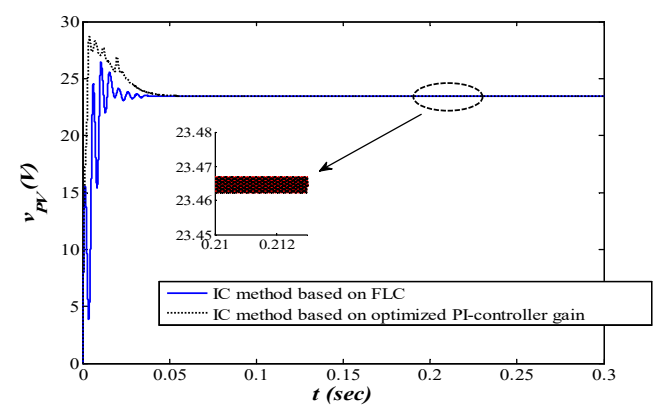

Figure 16. PV module voltage response under NOCT 


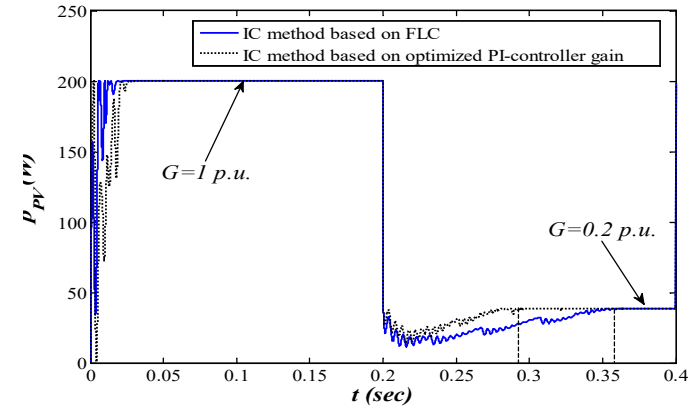

Figure 17. PV module power response under the worst atmospheric condition in the irradiance level change (at $\left.\mathrm{T}=25^{\circ} \mathrm{C}\right)$

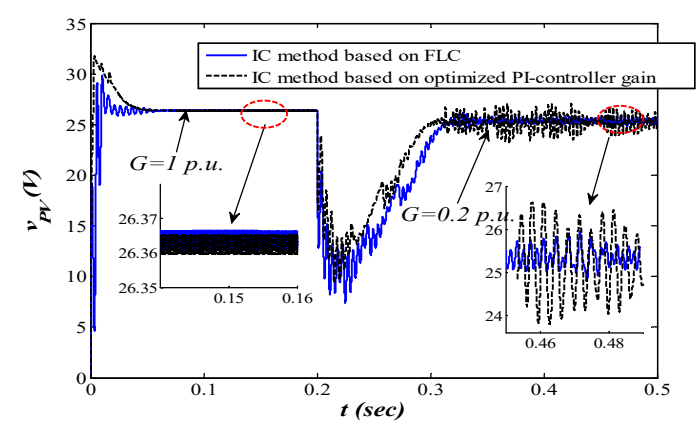

Figure 19. PV module voltage response under the worst atmospheric condition in the irradiance level change (at $\mathrm{T}=25^{\circ} \mathrm{C}$ )

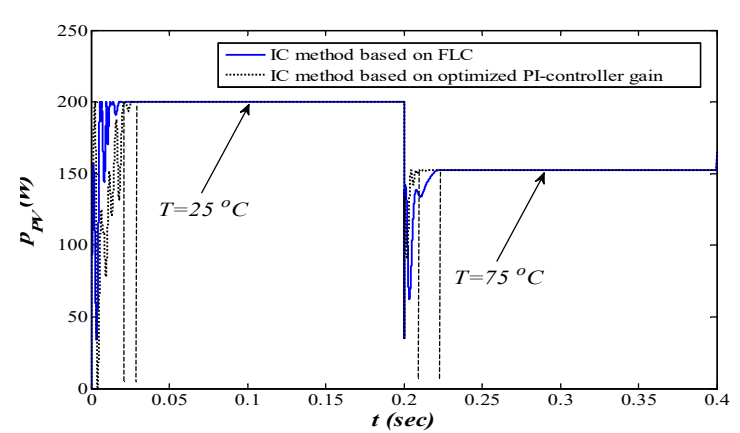

Figure 18. PV module power response under the worst atmospheric condition in the PV cell temperature change (at $\mathrm{G}=1$ p.u.)

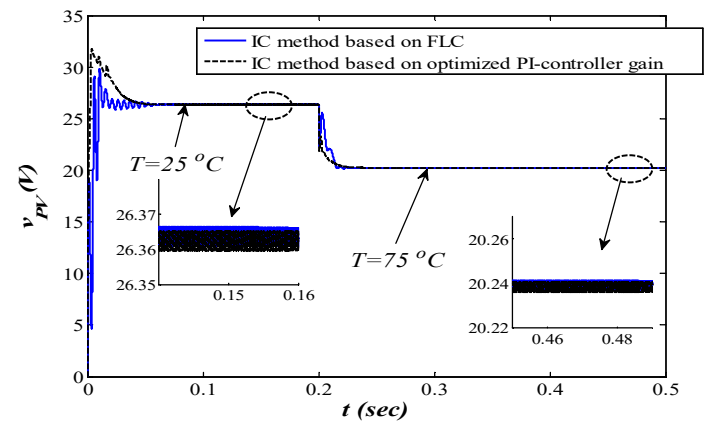

Figure 20. PV module voltage response under the worst atmospheric condition in the PV cell temperature change (at $\mathrm{G}=1$ p.u.)

\section{CONCLUSION}

In this paper, the tracking of MPP in a standalone PV system has been discussed. Two MPPT controllers have been modeled and simulated using Matlab/Simulink at different atmospheric conditions. The simulation results are verified with the experimental results which in the PV module manufacture datasheet [17]. The comparison criteria that taken into consideration are: the percentage tracking factor, the tracking time, the ripple voltage in the steady-state, the dynamic response, and the complexity of the controller. It can be concluded that both methods are almost $100 \%$ of tracking factor and the maximum peak to peak fluctuation of the PV module power is nearly zero. The IC method based on FLC algorithm has a better steady-state performance at the NOCT and at the worst atmospheric conditions compared to IC method based on optimized PI-controller gains algorithm. However, the dynamic performance of the PV system using the IC method based on optimized PI-controller gains algorithm is better than that using the IC method based on FLC algorithm. The PV system using the IC method based on FLC does not require offline computational processes but it depends on the skill of the designer when designing the membership functions and selecting the appropriate fuzzy rules. However, The PV system using the IC method based on optimized PI-control gains requires offline computational processes to optimize the integral controller gain.

\section{REFERENCES}

[1] S. N. Sakib, S. P. Mouri, Abu Kowsary, M. Rahamany, and M. Shamim Kaiser, "Theoretical Efficiency of AlAs/GaAs/GaAs0.91Bi0.085 Based New Multijunction Solar Cell and Effects of Solar Radiation and Sun Concentration on it," International Conference on Microelectronics, Computing and Communications (MicroCom), 23-25 Jan. 2016, pp. 1-6.

[2] M. A. Gomes de Brito, L. Galotto, Jr., L. P. Sampaio, G. de Azevedo e Melo, and C. A. Canesin, "Evaluation of the Main MPPT Techniques for Photovoltaic Applications," IEEE Transactions on Industrial Electronics, vol. 60, no. 3, pp.1156-1167, March 2013. 
[3] Mei Shan Ngan and Chee Wei Tan, "A Study of Maximum Power Point Tracking Algorithms for Stand-alone Photovoltaic Systems," Applied Power Electronics Colloquium (IAPEC), Johor Bahru, Malaysia, 8-19 April 2011, pp. 22-27.

[4] M. S. Ebrahim, A. M. Atallah, and A. S. Emarah, "Maximum Power Point Tracking for PV System using Fuzzy Logic Control," Fut International Conference on New Energy and Environmental Engineering (ICNEEE), 11-14 April 2016, pp. 157-162.

[5] XIE Wei and HUI Jing, "MPPT for PV System Based on A Novel Fuzzy Control Strategy," International Conference on Digital Manufacturing \& Automation, 18-20 December 2010, pp. 960-963.

[6] Trishan Esram and Patrick L. Chapman, "Comparison of Photovoltaic Array Maximum Power Point Tracking Techniques," IEEE Transactions on Energy Conversion, Vol. 22, No. 2, pp. 439-449, June 2007.

[7] Jadhav Pankaj Shankarrao, "FPGA Implementation of Maximum Power Point Tracking Algorithm for PV System," Master Thesis, National Institute of Technology Rourkela, May 2013.

[8] Ahmed K. Abdelsalam, Ahmed M. Massoud, Shehab Ahmed, and Prasad N. Enjeti, "High-Performance Adaptive Perturb and Observe MPPT Technique for Photovoltaic-Based Microgrids," IEEE Transactions on Power Electronics, Vol. 26, No. 4, pp. 1010-1021, April 2011.

[9] Moein Jazayeri, Sener Uysal, and Kian Jazayeri, "Evaluation of Maximum Power Point Tracking Techniques in PV Systems Using MATLAB/Simulink," Sixth Annual IEEE Green Technologies Conference, 3-4 April 2014, pp. 54-60.

[10] Gaber El Saady, El Noby Ahmed, and Samy Faddel, "Analysis and Control of Standalone PV/Battery Generation System," 16th International Middle- East Power Systems Conference -MEPCON'2014, Ain Shams University, Cairo, Egypt, December 23-25, 2014.

[11] Jay Robert B. del Rosario and Elmer Dadios, "Development of a Fuzzy Logic- Based PV Solar Tracking System Simulated Using QT Fuzzy Engine," 7th IEEE International Conference on Humanoid, Nanotechnology, Information Technology Communication and Control, Environment and Management (HNICEM), Philippines, 12-16 November 2014, pp. 1-8.

[12] Subiyanto, Azah Mohamed, and M. A. Hannan, "Hardware Implementation of Fuzzy Logic Based Maximum Power Point Tracking Controller for PV Systems," The 4th International Power Engineering and Optimization Conf. (PEOCO2010), Shah Alam, Selangor, Malaysia, 23-24 June 2010, pp. 435-439.

[13] Marcelo Gradella Villalva, Jonas Rafael Gazoli, and Ernesto Ruppert Filho, "Comprehensive Approach to Modeling and Simulation of Photovoltaic Arrays," IEEE Transactions on Power Electronics, Vol. 24, No. 5, pp. 1198-1208, May 2009.

[14] M. Petkov, D. Markova, and St. Platikanov, "Modelling of Electrical Characteristics of Photovoltaic Power Supply Sources," Contemporary Materials (Renewable energy sources), pp. 171-177, 2011.

[15] K.H. Hussein, I. Muta, T. Hoshino, and M. Osakada, "Maximum Photovoltaic Power Tracking: An Algorithm for Rapidly Changing Atmospheric Conditions," IEE Proceedings- Generation, Transmission and Distribution, Vol. 142, no. 1, pp. 59-64, Jan 1995.

[16] Heba N. Mohamed and Soliman A. Mahmoud, "Temperature Dependence in Modeling Photovoltaic Arrays," 20th International Conference on Electronics, Circuits, and Systems (ICECS), 8-11 December 2013, pp. 747-750.

[17] KC200GT High Efficiency Multicrystal Photovoltaic Module Datasheet Kyocera. [Online]. Available: http://www.kyocera.com.sg/products/solar/pdf/kc200gt.pdf.

[18] Mona Marodkar, Sarala Adhau, Manisha Sabley, and Praful Adhau, "Design and Simulation of DC-DC Converters for Photovoltaic System based on MATLAB," 2015 International Conference on Industrial Instrumentation and Control (ICIC) College of Engineering Pune, India, May 28-30, 2015, pp. 1478-1483.

[19] S. Kolsi1, H. Samet, and M. Ben Amar, "Design and Analysis of DC-DC Converters Connected to a Photovoltaic Generator and Controlled by MPPT for Optimal Energy Transfer throughout a Clear Day," Journal of Power and Energy Engineering (JPEE), Vol. 2, No. 1, pp. 27-34, January 2014.

[20] Mahmoud M. Hussein, "Control of a Stand-Alone Photovoltaic Energy System," Fut International Conference on New Energy and Environmental Engineering (ICNEEE), 11-14 April 2016, pp. 191-197.

[21] Ganji Sai Kumar, G. Ramudu, and D. Vijay Arun, "Analysis and Implementation of Bidirectional DC to DC Converter by Using Fuzzy Logic Controller," The International Journal of Engineering and Science (IJES), Vol. 3, no. 6, pp. 22-39, 2014.

[22] B. Stalin and T. S. Sivakumaran, "Performance Evaluation of Bidirectional Soft Switching Converter with Implementation of PI and Fuzzy Logic Controllers," International Journal of Advanced Engineering Technology," Vol. 8, no. 3, July-September 2016, pp. 42-53.

[23] Jaw-Kuen Shiau, Yu-Chen Wei, and Bo-Chih Chen, "A Study on the Fuzzy-Logic-Based Solar Power MPPT Algorithms Using Different Fuzzy Input Variables,” Algorithms, Vol. 8, pp. 100-127, 2015.

Int. J. of Adv. in Appl. Sci. Vol. 8, No. 1, March 2019: 73 - 82 